\section{Psychological Torture: Definition, evaluation and measurement, By Pau Pérez-Sales}

\author{
Published by Routledge (ISBN: 978- \\ 1138671553)
}

\section{Jim Jaranson, MD, MA, MPH}

Psychiatrist Pau Pérez-Sales has compiled a masterful and thorough analysis of an ambiguous but extremely important topic using a multidisciplinary approach. The book's objectives are to define torture, to build a theoretical framework for understanding and re-defining torture, to propose operational criteria for research, to propose working criteria for deciding whether a case constitutes torture and, finally, to propose adjustments in the Istanbul Protocol for documentation of torture. The author has accomplished all of these objectives successfully in a book that is well-written and easy to read, even though he draws from the esoteric concepts and language of legal, political, and scientific fields.

The definition of psychological torture has little consensus in the field. Considerable differences arise from the needs of researchers to have objective scientific criteria, for mental health clinicians to help survivors in treatment, for lawyers and judges to assess forensic cases, and for governments and human rights advocates to prevent torture. Psychological torture, as defined by PérezSales, is "the use of techniques of cognitive, emotional or sensory attacks that target the conscious mind and cause psychological suffering, damage and/or identity breakdown in most subjects ..."

This book begins with an historical review of definitions which provide a basis for contemporary review of the definition. The related and overlapping concept of CIDT (Cruel, Inhuman, and Degrading Treatment) or punishment in international law is compared with torture. This detailed history smoothly paves the way to the contemporary review of the definition and recommendations for the future.

The next two sections include case presentations of survivors and of perpetrators with a detailed analysis of the relevance for a discussion of psychological torture. This is particularly noteworthy, a valuable and innovative approach to this topic.

Subsequently, Pérez-Sales discusses how psychological torture has gained recognition in international law, how humiliation serves to differentiate legal and mental health perspectives, and how the perpetrator justifies his motivation, intention, and purpose.

Adding scientific approaches to the discussion, the author concludes that, rather than cataloguing torture methods, emphasis should focus on the objectives of torture. Using newer biological techniques such as neuroimaging have shown correlates of torture but perhaps the future will provide greater specificity. Discussions about trauma, which itself has no satisfactory definition, have provided insights from clinical psychiatry for psychological torture theory.

Next follows a lengthy section of techniques of psychological torture beginning with a discussion of the French, British, and American schools of psychological torture and their historical convergence. This section continues with the influence of 
the environmental manipulation and coercive interrogation, the targeting of the body to reach the mind, interrogation for both law enforcement and military intelligence gathering, psychological manipulation of identity, i.e., brainwashing, and the use of technological research vis a vis psychological torture.

Finally, Pérez-Sales integrates and summarizes the conceptual "map" of torture based upon his work as described earlier in the book, proposes new ways to define and measure torture environments, suggests ways to improve the Istanbul Protocol, and proposes an agenda for research in the future.

This book should be available to everyone with an interest in politically-motivated torture and its treatment. It has multiple potential uses as a textbook, a reference work, or just as an interesting book for those who need or want to know about psychological torture. The many charts, tables, research instruments, references, and appendices can be useful for reference or in training.

This book has few limitations or shortcomings. The ones I can find are minor. For example, "tones" on page 8 is ambiguous and could refer either to audible or visual tones. The general attorney of the United States (page 273) should be attorney general. Table 10.2 (page 167) should include the mental health work of early North American torture treatment centers: PTV in Los Angeles, 1980; CCTV in Toronto, 1982, CVT in Minneapolis, 1985.

Personally, I find the book extremely interesting and have learned new information and approaches to the topic, even though I've had more than thirty years of clinical, research, training, and administrative experience as a psychiatrist in the field of torture rehabilitation. The book has summarized the history of methods worldwide, the evolution of definitions, and conceptualized the concept of psychological torture in ways that I found creative and most useful.

Pérez-Sales has accessed material that has only been published in Spanish and would be missed by those limited to the English language literature, documents and testimonies.

Of particular use for reference are the eight appendixes: 1) classification systems for torture methods, 2) the CIA and Army interrogation manuals, 3) classification of interrogation techniques, 4) the Torturing Environment Scale (TES), 4) a toolbox of assessment instruments, 5) the Standard Evaluation Form for Credibility Assessment (SEC), 7) the Intentionality Assessment Checklist (IAC), and 8) a guide to documenting torture.

I strongly recommend the book as necessary for anyone working in or with an interest in politically-motivated torture and its rehabilitation--for mental health practitioners, researchers or forensic experts, policy-makers and as a necessary reference work for many others. Pérez-Sales has brought together in an eloquent text what is known and needs to be known "from all possible angles...testimonies, studies, opinions, reports, laws, and facts" (page 258). Much of the content can be found piecemeal elsewhere but, as Alexander Pope stated in 1711, the book contains "What oft was thought but ne'er so well express'd." I appreciate the incredible effort that PérezSales expended in researching and writing this book as a single author--but I am most appreciative that he did.

This book will complement the volume edited by another psychiatrist and researcher, Metin Başoğlu: Torture and its Definition in International Law: An Interdisciplinary Approach, scheduled for publication by Oxford University Press in August, 2017. 